\title{
Comparative Analysis of Compact Satellite Polarizers Based on a Guide with Diaphragms
}

\author{
Stepan Piltyay', Andrew Bulashenko', Iryna Fesyuk', and Oleksandr Bulashenko² \\ ${ }^{1}$ Department of Theoretical Foundations of Radio Engineering, National Technical University of Ukraine "Igor Sikorsky Kyiv Polytechnic Institute", \\ Kyiv, Ukraine \\ ${ }^{2}$ Electromechanical Department, Ivan Kozhedub Shostka Professional College of Sumy State University, Shostka, Ukraine \\ Corresponding author: Stepan Piltyay (e-mail: crosspolar@ukr.net)
}

\begin{abstract}
In this article we carry out the comparative analysis of new compact satellite polarizers based on a square guide with diaphragms. The main electromagnetic parameters of the developed microwave guide devices with various amount of diaphragms were obtained within the satellite frequency interval from $10.7 \mathrm{GHz}$ to $12.75 \mathrm{GHz}$. Waveguide polarization converters with different amount of diaphragms from 3 to 5 have been designed and optimized. The main parameters of the presented polarizer were calculated applying the numerical method of finite integration in the frequency domain. Optimization of the electromagnetic parameters of the developed waveguide devices was carried out using the finite elements method in the frequency domain. As a result, sizes of the guide polarizer design have been optimized for the provision of improved polarization and phase parameters. The performed analysis showed that a waveguide polarizer with five diaphragms has the best electromagnetic parameters. The developed compact polarizer with five diaphragms based on a square guide provides a minimum deviation of the output phase difference from 90 degrees and high level of isolation between linear polarization over the entire operating frequency range. Presented in the article compact waveguide polarization converters can be applied in modern satellite systems, which require efficient polarization transformation and separation of signals.
\end{abstract}

INDEX TERMS waveguide polarizer, diaphragms polarizer, microwave devices, waveguide components, electromagnetic simulation, circular polarization, output phase difference, isolation of linear polarization.

\section{INTRODUCTION}

T $\mathrm{HE}$ allocation of operating frequency bands to users of different systems and appliances is strictly regulated and monitored. Due to this reason the information capacity of wireless mobile, satellite and other communication channels is limited. Therefore, nowadays the economy and management of this limited and expensive resource is of crucial importance. This leads to the occurrence of radio engineering techniques of the repeated utilization of the allocated to user frequency range. One of the most promising methods of frequency reuse is achieved in the antennas and systems applying simultaneous operation at two linear or circular orthogonal polarizations with high isolation between the independently transmitted signals. This effective radio engineering solution allows to double information capacity of the applied wireless channel with an allocated frequency band.

The impact of polarization type on the process of electromagnetic waves' propagation is of critical importance [1-3]. The fading effect in wireless systems can be reduced in the case of application of circular polarization type of the transmitted signals [3-10]. The signals, which are reflected from the environmental objects odd times, will possess orthogonal polarization with respect to the transmitted one. In this case the interfering electromagnetic waves will be reflected by the receiving antenna of the wireless system. In addition, the utilization of circular polarization kind in space telecommunications allows to transmit and receive signals from rotating around the communication line direction satellites and aircrafts [3-5]. Besides, the influence of Faraday effect in the atmosphere on wireless transmission quality is negligible for the signals transmitted by circularly polarized waves [1-5]. This peculiarity plays an important role in the telemetry and radio control of ballistic missiles.

A waveguide polarizer is a device of antenna feed network, which converts electromagnetic modes with circular polarizations into linearly polarized or vice versa. Consequently, this waveguide component determines main parameters of the antenna system, such as output phase difference, reflection factor, transmission factor and isolation of linear polarizations (ILP).

\section{Designs of modern waveguide polarizers}

A waveguide polarizer with longitudinal septum is the most frequently used kind of polarization converters and dividers [11-25]. The main benefit of this polarizer consists in its compact structure, which combines the functions of an orthogonal mode selector and polarization converter. The disadvantage of a polarizer with longitudinal septum is 
its narrow operating frequency band. Recently, a new septum polarizer was proposed in [11] for the application in an antenna without mechanical switching between right and left hand circular polarizations (LHCP and RHCP). In [12] a model of a new septum polarizer with stepped ridge transitions in a rectangular waveguide was proposed. The numerical analysis of a septum polarizer was carried out using computer simulation in [13]. A compact septum polarizer with two steps in the frequency range $8-9 \mathrm{GHz}$ is presented in [16]. Another design of a waveguide septum polarizer with a cone-shaped form was proposed in [17].

In [18] it was found by the authors that the relative bandwidth of a septum polarizer can reach only $20 \%$ if the isolation between rectangular waveguide ports is higher than $25 \mathrm{~dB}$ and ILP is higher than $30 \mathrm{~dB}$. Another septum polarizer with an integrated transition from a square to a circular guide was tested in [19]. Measured characteristics correlate with values obtained by CST Microwave Studio in the band of 18.5-21.5 GHz. In [20] a broadband septum polarizer was developed for new antenna system operating in the frequency band $8-12 \mathrm{GHz}$. It provides the simultaneous operation at two orthogonal circular polarizations. In [21] a septum polarizer design was proposed for the range 27.5-30.0 GHz. The longitudinal profile of the septum was formed using Legendre polynomials. The new design of a compact waveguide duplexer that operates at a frequency of $225 \mathrm{GHz}$ is presented in [22]. It applied a septum polarizer to operate at circular polarization. Developed guide device provides 30 $\mathrm{dB}$ isolation over a $10 \%$ bandwidth. In $[23,24]$ the authors presented a compact polarizer with a stepped thickness septum for the range of 7.7-8.5 GHz. The minimum crosspolarization isolation value is $30 \mathrm{~dB}$. A new polarizer with a bandwidth of $37.8 \%$ based on a triangular waveguide was proposed in [25]. This polarizer was developed for two different frequency ranges $18-26 \mathrm{GHz}$ and $75-110 \mathrm{GHz}$. Its ellipticity coefficient does not exceed $1.3 \mathrm{~dB}$.

Another frequently used device for polarization transformation is a guide polarizer with diaphragms [2643]. It allows to obtain better performance in wider relative bandwidths. The main disadvantage of the diaphragm-based polarizer design consists in greater complexity of the resulting antenna feed network, which must contain separate polarization converter and an orthogonal modes selector [26]. The benefit of a polarizer with diaphragms is its axial mirror symmetry with respect to two perpendicular planes, which improves the polarization purity, decreases higher modes excitation and allows simple fabrication by the highly accurate and efficient CNC milling technology.

In [27] researchers carried out the analysis of main polarizer's characteristics sensitivity to the alteration of its geometrical dimensions. The process of optimization of a polarizer based on a circular waveguide with elliptical diaphragms is presented in [28]. The authors of [29] developed a new polarizer-rotator with diaphragms based on a square waveguide. A developed polarizer with six diaphragms provides a phase shift of $180^{\circ} \pm 2^{\circ}$ in the operating band of 12.8-14.2 GHz. In [30, 31], the authors proposed a method for the development of waveguide polarizers with diaphragms. As a result, Ka-band polarizers with a bandwidth of $10 \%$ were developed. They provided an excellent output phase difference of $90^{\circ} \pm 1^{\circ}$.

A new method for the development of dual-band polarizers based on a square waveguide with diaphragms was proposed in [32]. As a result, a new guide polarizer was designed for the operation in $20.8-21.2 \mathrm{GHz}$ and 30.6 $31.0 \mathrm{GHz}$ bands using the HFSS software. Another design of a dual-band waveguide polarizer was developed in [33]. This guide polarizer was designed for the simultaneous operation in two bands: $25-26 \mathrm{GHz}$ and $34-35 \mathrm{GHz}$. In both bands it provides an ellipticity factor of less than 0.4 $\mathrm{dB}$. In [34] a design of a waveguide polarizer with diaphragms was proposed for the antenna feed system operating in the satellite C-band. The field theory of modes propagating in a diaphragm polarizer for satellite applications is considered in [36]. A comparison of theoretical and simulated characteristics was made in the research. In [37] a new design of a broadband diaphragm polarizer for the operating frequency band $3.4-4.8 \mathrm{GHz}$ is presented. The developed polarizer provides an output phase difference of $90^{\circ} \pm 2.5^{\circ}$ with a maximum reflection factor of $-33 \mathrm{~dB}$. Another efficient design of a waveguide polarizer for the frequency range $85-115 \mathrm{GHz}$ was proposed in [38]. Designed polarizer provides an output phase difference of $90^{\circ} \pm 3.3^{\circ}$ at the output port with a maximum value of the ellipticity factor of $0.6 \mathrm{~dB}$. In [40] the authors developed a new feed network for the reflector antennas operating in the C-band 3.4-4.8 GHz. Voltage standing wave ratio of the network did not exceed 1.14. In [41-43] several designs of polarizers based on a square guide with a different number of diaphragms were developed for use in antennas for satellite communications.

Higher order of the structure's symmetry and lower higher-order modes excitation can be achieved using the guides with the symmetries of $\mathrm{C} 4$ or $\mathrm{C} \infty$ kinds. These highly symmetrical designs are based on the guides of sectoral [44, 45] and quad-ridged types [46, 47]. Several kinds of polarization converters and orthogonal modes selectors based on mentioned guides were suggested in [48-54]. The drawback of sectoral and quad-ridged guides is the complexity of their fabrication process, the impossibility of fine tuning and calibration.

In [55-60] various guide polarizers with diaphragms in the form of slots in circular and square waveguides are presented. In addition, the phenomenon of optical activity is suggested for the development of novel polarizers with diaphragms in the form of slots in a rectangular waveguide $[55,56]$. The designs of such polarizers contained four slotbased diaphragms. In [57] a design of a polarizer based on a structure with two-sided symmetry is presented. A new tunable design of a polarizer based on a circular slot waveguide was proposed in [58]. The design of a polarizer with diaphragms in the form of slots was presented in [60]. The structure is formed by resonant diaphragms with 
rectangular slots. This design provided a phase shift of $90^{\circ}$ for various operating frequency ranges.

The new designs of polarizers with posts in circular and square waveguides are presented in [61-68]. The results of experimental and numerical simulation of characteristics of cylindrical posts in circular and rectangular waveguides are published in $[61,62]$. It has been shown that it is possible to expand the range by increasing the number of posts and changing their lengths. Some other research [63, 64] studied the scattering characteristics of a circular and rectangular waveguides loaded by posts. In [65] the scattering characteristics of a section of a rectangular waveguide with opposite-located posts were investigated. The design of a tunable posts-based guide polarizer for the $\mathrm{Ku}$-band was proposed in [66]. Adjustment is accomplished by installing a pair of movable metal posts. In [67] the design of a compact mode converter using rectangular metal posts in a circular waveguide is presented. The design of a waveguide resonator with posts was proposed in [68]. In [69] a technique for designing of waveguide polarizers with cylindrical posts is presented. A waveguide polarizer section with a combined structure of posts and diaphragms was proposed in [70]. This section can provide differential phase shift of $45^{\circ}$ and $90^{\circ}$. Other designs of tunable polarizers based on a guide with diaphragms and posts are presented in [71, 72]. A fast technique for designing of polarizers with cylindrical posts was proposed in [73].

In [74-79] the authors developed various theoretical methods for the calculation of characteristics of guide polarizers using the analysis of electromagnetic fields, wave scattering matrices, and approximate approximation techniques for coaxial and ridged structures. The parametric synthesis of square polarizers with diaphragms was performed in [80-85]. In [80, 81] a new method was developed to analyze polarizers with diaphragms based on microwave scattering and transmission matrices. The main electromagnetic parameters of the device were expressed through the elements of the matrices. In [82] the authors developed a method for analysis of waveguide polarizers based on equivalent circuits. In [83] a parametric analysis of guide polarizer for the operating range $3.4-4.2 \mathrm{GHz}$ was carried out. The optimization and development of a polarizer based on a square guide with two diaphragms with the account of their thickness was carried out in $[84,85]$.

The designs of polarizers for the millimeter wave range of modern $5 \mathrm{G}$ systems are presented in [86-92]. In [86] it was proposed to use a horn antenna with a built-in waveguide polarizer to obtain broadband polarized radiation mode. In $[87,88]$ circularly polarized antenna arrays based on a guide polarizer are presented. A new polarizer for circularly polarized finite-radiation antennas in 5G mobile devices was proposed in [91]. The developed polarizer has a partition integrated into the substrate. The purity of polarization is improved by the application of metallized slots. The $29 \mathrm{GHz}$ polarizer maintains an ellipticity factor of less than $3 \mathrm{~dB}$ over a $4.5 \%$ bandwidth. Research [94] presents a simple and accurate methodology for the complete characterization of septum polarizer for $5 \mathrm{G}$ applications. The developed technique was applied for the polarizer operating in Ku-band.

Typically, a waveguide polarizer provides good matching for propagating electromagnetic modes of both orthogonal polarizations. The amplitudes of field components with orthogonal linear polarizations at the polarizer's input and output are equal with high accuracy. In fact, any fabricated guide polarizer has imperfect matching. Thus, to calculate the polarization characteristics (ellipticity and ILP at the output) of a polarizer one must take into account the deviations between amplitudes of field vectors with perpendicular linear polarizations at the output port.

The comparison of optimal compact structures of guide polarizers with diaphragms and determination of their sizes for a specified frequency band of satellite systems remains a relevant problem, which is solved in the article. Besides, most part of the research on polarizers base the calculation of all polarization characteristics only on the differential phase shift introduced by the polarizer. Therefore, additional novelty of the presented article consists in the account of difference between the amplitudes of orthogonally polarized field components simultaneously with the output phase difference between them in guide polarizers.

The ellipticity ratio, ILP at the polarizer's output along with the output phase difference, reflection factor and transmission factor for the modes of two perpendicular polarizations will be simultaneously considered for the optimization of polarizers. The goals of optimization are obtaining of reflection factors for waves with perpendicular linear polarizations less than $-24 \mathrm{~dB}$ and of IPL higher than $30 \mathrm{~dB}$ in the operating frequency band $10.7-12.75 \mathrm{GHz}$.

\section{Working mechanism of a guide polarizer and its polarization characteristics}

Any polarizer does not provide ideal equality of the amplitudes of orthogonal linearly polarized components at its output in the whole operating frequency band. Besides, the polarizer does not introduce differential phase shift, which is exactly equal to required $90^{\circ}$ in the whole operating frequency band. Consequently, accurate theoretical formulas must be applied to estimate the phase and polarization characteristics of a guide polarizer.

In the general case complex amplitudes of electric field vectors of the fundamental electromagnetic modes $\mathrm{TE}_{10}$ with perpendicular vertical and horizontal linear polarizations lie in the transversal plane and can be written as follows:

$$
\dot{\vec{E}}_{v e r t}=E_{v} e^{i \varphi_{v}} \vec{v} ; \quad \dot{\vec{E}}_{h o r}=E_{h} e^{i \varphi_{h}} \vec{h},
$$

where $E_{v}$ and $E_{h}$ denote the amplitudes of corresponding electric fields directed along the unit vectors $\vec{v}$ and $\vec{h}$ of the perpendicular vertical and horizontal axes, respectively. Symbols $\varphi_{v}$ and $\varphi_{h}$ stand for the phases of the main electromagnetic waves at the output port of a guide polarization converter.

Now we us introduce the average phase and the phase difference as follows: $\varphi_{0}=\left(\varphi_{v}+\varphi_{h}\right) / 2 ; \Delta \varphi=\varphi_{h}-\varphi_{v}$. 
Then the phases $\varphi_{v}$ and $\varphi_{h}$ are expressed as follows:

$$
\varphi_{v}=\varphi_{0}-\Delta \varphi / 2 ; \quad \varphi_{h}=\varphi_{0}+\Delta \varphi / 2 .
$$

After this the substitution of (2) into the expressions (1) is carried out. Then the superposition of two orthogonal fundamental modes with perpendicular linear polarizations at the output port of a guide polarizer is as follows:

$$
\begin{aligned}
\dot{\vec{E}}_{\text {sup }}=\dot{\overrightarrow{\vec{E}}}_{\text {vert }} & +\dot{\overrightarrow{\vec{E}}}_{h o r}=E_{v} e^{i\left(\varphi_{0}-\Delta \varphi / 2\right)} \vec{v}+E_{h} e^{i\left(\varphi_{0}+\Delta \varphi / 2\right)} \vec{h}= \\
& =e^{i \varphi_{0}}\left(E_{v} e^{-i \Delta \varphi / 2} \vec{v}+E_{h} e^{i \Delta \varphi / 2} \vec{h}\right) .
\end{aligned}
$$

Next, we find components with LHCP and RHCP ( $\dot{L}$ and $\dot{R}$ ) of the total complex amplitude (3):

$$
E_{v} e^{-i \Delta \varphi / 2} \vec{v}+E_{h} e^{i \Delta \varphi / 2} \vec{h}=\dot{L}\left(\vec{e}_{v}+i \cdot \vec{e}_{h}\right)+\dot{R}\left(\vec{e}_{v}-i \cdot \vec{e}_{h}\right) .
$$

Now we can separate two linear equations relative to the amplitudes $\dot{L}, \dot{R}$ and solve the following system:

$$
\left\{\begin{array}{c}
\dot{L}+\dot{R}=E_{v} e^{-i \Delta \varphi / 2} \\
\dot{L}-\dot{R}=-i E_{h} e^{i \Delta \varphi / 2}
\end{array} .\right.
$$

To solve this set, it is enough to consequently add and subtract equations (4). The result will be as follows:

$$
\left\{\begin{array}{l}
2 \dot{L}=E_{v} e^{-i \Delta \varphi / 2}-i E_{h} e^{i \Delta \varphi / 2} \\
2 \dot{R}=E_{v} e^{-i \Delta \varphi / 2}+i E_{h} e^{i \Delta \varphi / 2}
\end{array}\right.
$$

Let us divide equations of the set (5) by 2 and use Euler formulas to find the complex amplitudes $\dot{L}$ and $\dot{R}$ :

$$
\begin{aligned}
& \dot{L}=\frac{1}{2}\left(E_{v} \cos \frac{\Delta \varphi}{2}-i E_{v} \sin \frac{\Delta \varphi}{2}-i E_{h} \cos \frac{\Delta \varphi}{2}+E_{h} \sin \frac{\Delta \varphi}{2}\right) ; \\
& \dot{R}=\frac{1}{2}\left(E_{v} \cos \frac{\Delta \varphi}{2}-i E_{v} \sin \frac{\Delta \varphi}{2}+i E_{h} \cos \frac{\Delta \varphi}{2}-E_{h} \sin \frac{\Delta \varphi}{2}\right) .
\end{aligned}
$$

Next, we must obtain the modules of the last expressions for complex amplitudes and perform their simplification. These transformations will lead us to the following formulas:

$$
\begin{aligned}
& L=\frac{1}{2} \sqrt{E_{v}{ }^{2}+E_{h}{ }^{2}+2 E_{v} E_{h} \sin \Delta \varphi} ; \\
& R=\frac{1}{2} \sqrt{{E_{v}}^{2}+E_{h}{ }^{2}-2 E_{v} E_{h} \sin \Delta \varphi} .
\end{aligned}
$$

Now we will find the ellipticity coefficient for the considered sum of electromagnetic modes with LHCP and RHCP with corresponding complex amplitudes $\dot{L}$ and $\dot{R}$. General complex amplitudes vectors of these two electromagnetic waves are expressed as follows:

$$
\dot{\vec{E}}_{\mathrm{LHCP}}=L \cdot e^{i \varphi_{L}}\left(\vec{e}_{v}+i \cdot \vec{e}_{h}\right) ; \dot{\vec{E}}_{\mathrm{RHCP}}=R \cdot e^{i \varphi_{R}}\left(\vec{e}_{v}-i \cdot \vec{e}_{h}\right) .
$$

To perform the transformations, we separate the central phase and phase difference between the LHCP and RHCP electromagnetic waves with amplitudes (8) as follows:

$$
\varphi_{0 \mathrm{CP}}=\frac{\varphi_{L}+\varphi_{R}}{2} ; \Delta \varphi_{\mathrm{CP}}=\varphi_{R}-\varphi_{L} .
$$

These denotations allow us to rewrite the phases of orthogonal LHCP and RHCP components as follows:

$$
\varphi_{L}=\varphi_{0 \mathrm{CP}}-\Delta \varphi_{\mathrm{CP}} / 2 ; \quad \varphi_{R}=\varphi_{0 \mathrm{CP}}+\Delta \varphi_{\mathrm{CP}} / 2 .
$$

Having applied the introduced denotations (9), we expand the sum complex amplitudes of two electromagnetic modes with the orthogonal circular polarizations at the output port of a guide polarizer:

$$
\begin{gathered}
\dot{\vec{E}}_{\mathrm{SuP}}=\dot{\vec{E}}_{\mathrm{LHCP}}+\dot{\vec{E}}_{\mathrm{RHCP}}= \\
=L \cdot e^{i\left(\varphi_{0 \mathrm{CP}}-\frac{\Delta \varphi_{\mathrm{CP}}}{2}\right)}\left(\vec{e}_{v}+i \cdot \vec{e}_{h}\right)+R \cdot e^{i\left(\varphi_{\mathrm{OCP}}+\frac{\Delta \varphi_{\mathrm{CP}}}{2}\right)}\left(\vec{e}_{v}-i \cdot \vec{e}_{h}\right)= \\
=e^{i \varphi_{0 \mathrm{CP}}\left[\vec{e}_{v}\left(L \cdot e^{-i \frac{\Delta \varphi_{\mathrm{CP}}}{2}}+R \cdot e^{i \frac{\Delta \varphi_{\mathrm{CP}}}{2}}\right)+\right.} \\
\left.+i \cdot \vec{e}_{h}\left(L \cdot e^{-i \frac{\Delta \varphi_{\mathrm{CP}}}{2}}-R \cdot e^{i \frac{\Delta \varphi_{\mathrm{CP}}}{2}}\right)\right] .
\end{gathered}
$$

The utilization of Euler formulas relatively to the last expression leads us to the following formula for the considered sum of complex amplitudes:

$$
\begin{aligned}
& \dot{\vec{E}}_{\text {sup }}=e^{i \varphi_{0 \mathrm{CP}}}\left[\vec { e } _ { v } \left(L \cos \frac{\Delta \varphi_{\mathrm{CP}}}{2}-i L \sin \frac{\Delta \varphi_{\mathrm{CP}}}{2}+\right.\right. \\
& \left.+R \cos \frac{\Delta \varphi_{\mathrm{CP}}}{2}+i R \sin \frac{\Delta \varphi_{\mathrm{CP}}}{2}\right)+ \\
& +i \vec{e}_{h}\left(L \cos \frac{\Delta \varphi_{\mathrm{CP}}}{2}-i L \sin \frac{\Delta \varphi_{\mathrm{CP}}}{2}-\right. \\
& \left.\left.-R \cos \frac{\Delta \varphi_{\mathrm{CP}}}{2}-i R \sin \frac{\Delta \varphi_{\mathrm{CP}}}{2}\right)\right]= \\
& =e^{i \varphi_{0 \mathrm{CP}}}\left[\vec{e}_{v}\left((L+R) \cos \frac{\Delta \varphi_{\mathrm{CP}}}{2}-i(L-R) \sin \frac{\Delta \varphi_{\mathrm{CP}}}{2}\right)+\right. \\
& \left.+i \vec{e}_{h}\left((L-R) \cos \frac{\Delta \varphi_{\mathrm{CP}}}{2}-i(L+R) \sin \frac{\Delta \varphi_{\mathrm{CP}}}{2}\right)\right]= \\
& =e^{i \varphi_{0 \mathrm{CP}}}\left[(L+R)\left(\vec{e}_{v} \cos \frac{\Delta \varphi_{\mathrm{CP}}}{2}+\vec{e}_{R} \sin \frac{\Delta \varphi_{\mathrm{CP}}}{2}\right)-\right. \\
& \left.-i(L-R)\left(\vec{e}_{v} \sin \frac{\Delta \varphi_{\mathrm{CP}}}{2}-\vec{e}_{R} \cos \frac{\Delta \varphi_{\mathrm{CP}}}{2}\right)\right]= \\
& =e^{i \varphi_{0 \mathrm{CP}}}\left[(L+R) \vec{e}_{1}-i(L-R) \vec{e}_{2}\right] \text {, }
\end{aligned}
$$

where $\vec{e}_{1}=\vec{e}_{v} \cos \frac{\Delta \varphi_{\mathrm{CP}}}{2}+\vec{e}_{h} \sin \frac{\Delta \varphi_{\mathrm{CP}}}{2}$;

$$
\vec{e}_{2}=\vec{e}_{v} \sin \frac{\Delta \varphi_{\mathrm{CP}}}{2}-\vec{e}_{h} \cos \frac{\Delta \varphi_{\mathrm{CP}}}{2} .
$$

Next, we obtain the modules of the vectors $\vec{e}_{1}$ and $\vec{e}_{2}$ :

$$
\begin{aligned}
& \left|\vec{e}_{1}\right|=\sqrt{\left(\cos \frac{\Delta \varphi_{\mathrm{CP}}}{2}\right)^{2}+\left(\sin \frac{\Delta \varphi_{\mathrm{CP}}}{2}\right)^{2}}=1 ; \\
& \left|\vec{e}_{2}\right|=\sqrt{\left(\sin \frac{\Delta \varphi_{\mathrm{CP}}}{2}\right)^{2}+\left(\cos \frac{\Delta \varphi_{\mathrm{CP}}}{2}\right)^{2}}=1 .
\end{aligned}
$$

Obtained values mean that $\vec{e}_{1}$ and $\vec{e}_{2}$ are unit vectors.

Let us calculate scalar product of vectors $\vec{e}_{1}$ and $\vec{e}_{2}$ : 
$\vec{e}_{1} \cdot \vec{e}_{2}=\cos \frac{\Delta \varphi_{\mathrm{CP}}}{2} \cdot \sin \frac{\Delta \varphi_{\mathrm{CP}}}{2}-\sin \frac{\Delta \varphi_{\mathrm{CP}}}{2} \cdot \cos \frac{\Delta \varphi_{\mathrm{CP}}}{2}=0$.

Cosine of the angle between vectors $\vec{e}_{1}$ and $\vec{e}_{2}$ is:

$$
\cos \left(\vec{e}_{1} ; \vec{e}_{2}\right)=\frac{\vec{e}_{1} \cdot \vec{e}_{2}}{\left|\vec{e}_{1}\right| \cdot\left|\vec{e}_{2}\right|}=0,
$$

which indicates that the geometrical angle between the considered unit vectors $\vec{e}_{1}$ and $\vec{e}_{2}$ is equal to $90^{\circ}$.

Therefore, we make a conclusion that the vectors $\vec{e}_{1}$ and $\vec{e}_{2}$ are unit coordinate vectors of the new inclined orthogonal coordinate system. They are parallel to the long $a$ and short $b$ axes of the polarization ellipse of electromagnetic wave at an output port. Thus, the ellipticity coefficient is the ratio between the modules of these axes.

As a result, we obtain ellipticity coefficient $p$ of the polarization ellipse from formula (10) as follows:

$$
p=\frac{a}{b}=\left|\frac{L+R}{L-R}\right| .
$$

Having substituted expressions (6) and (7) into the square of the formula (11), we obtain the following formula for the squared axial ratio of electromagnetic wave at the output port of a guide polarizer:

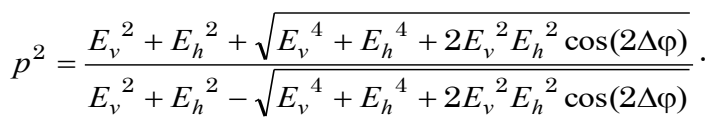

Another frequently applied value to characterize the polarization state of electromagnetic wave in guide polarizers, which is directly connected with the ellipticity coefficient, is isolation of linear polarizations. In the considered circular polarization basis it is equal to the ratio of the modules of LHCP and RHCP components. According to definition we obtain the following expression:

$$
\mathrm{ILP}=\frac{L}{R}=\frac{\sqrt{E_{v}{ }^{2}+E_{h}{ }^{2}+2 E_{v} E_{h} \sin \Delta \varphi}}{\sqrt{E_{v}{ }^{2}+E_{h}{ }^{2}-2 E_{v} E_{h} \sin \Delta \varphi}} .
$$

If a polarizer introduces phase shift $\Delta \varphi=90^{\circ}$ and the input electromagnetic mode with linear polarization has perpendicular in-phase components with equal amplitudes (i.e. the mode enters a polarizer with $45^{\circ}$ inclination angle), then $E_{v}=E_{h}$. Substitution of these values into (12) and (13) leads to the ellipticity coefficient $p= \pm 1$ and ILP $\rightarrow \infty$, which obviously indicates a circularly polarized electromagnetic wave at the output port of a polarizer.

\section{Diaphragm polarizer designs and their performance}

This section presents the results of comparative analysis of electromagnetic characteristics of compact polarization converters based on a square guide with different number of diaphragms in a design (from 3 to 5).

For computer modeling of considered characteristics we will apply finite elements method in the frequency domain. In [95-97] the authors have shown that mentioned method provides better convergence of the characteristics than FDTD method. Besides, the calculation time of finite elements method in frequency domain is twice less than that time of FDTD method.

\section{A. SQUARE GUIDE POLARIZER WITH THREE DIAPHRAGMS}

A three-dimensional inner view of a square guide polarizer with 3 diaphragms is shown in Fig. 1. In addition, all inner sizes of a structure are also presented in the figure. Denoted dimensions have been varying in the process of optimization of the square guide polarizer to bring its electromagnetic characteristics to the required values. The process of numerical optimization of presented microwave device involves changing of its dimensions in order to obtain the best characteristics in the operating frequency range. The diaphragms can be manufactured as integrated into a polarizer structure by milling of a single metal brick.

The middle diaphragm has a height of $h_{2}$. It is higher than the other two diaphragms of the same height $h_{1}$ to ensure better matching. The distance between diaphragms is $L_{1}$. All diaphragms have the same thickness $w$.
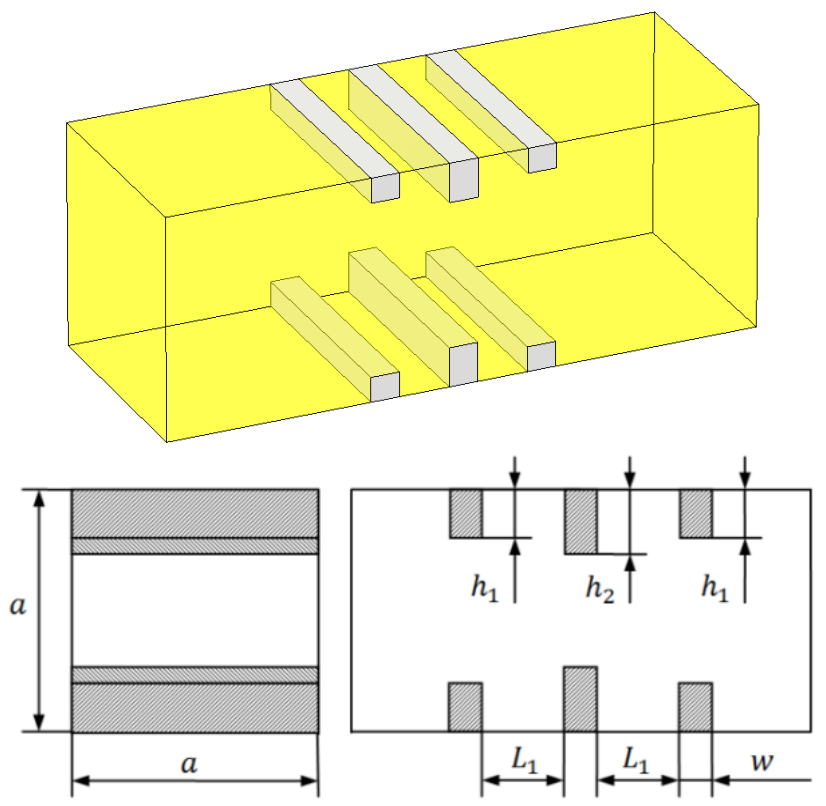

FIGURE 1.3-D model of a square guide polarizer with three diaphragms

Fig. 2 demonstrates main electromagnetic parameters of the compact square guide polarizer with three diaphragms in the operating Ku-band $10.7-12.75 \mathrm{GHz}$. 


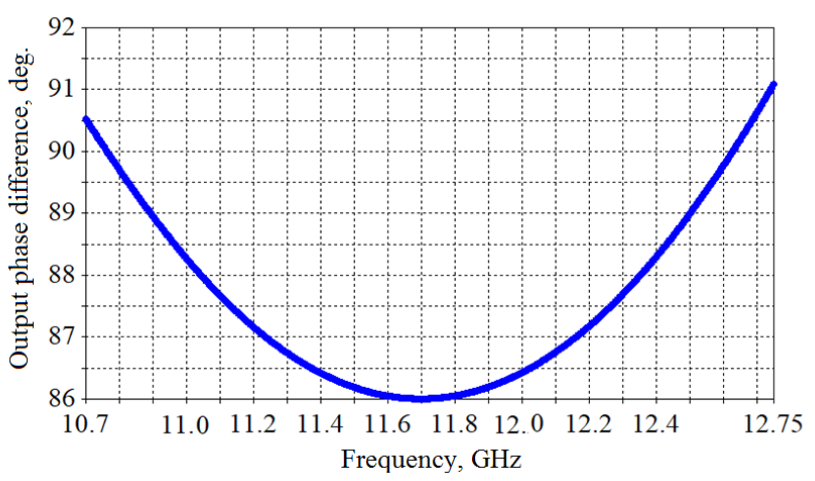

(a)

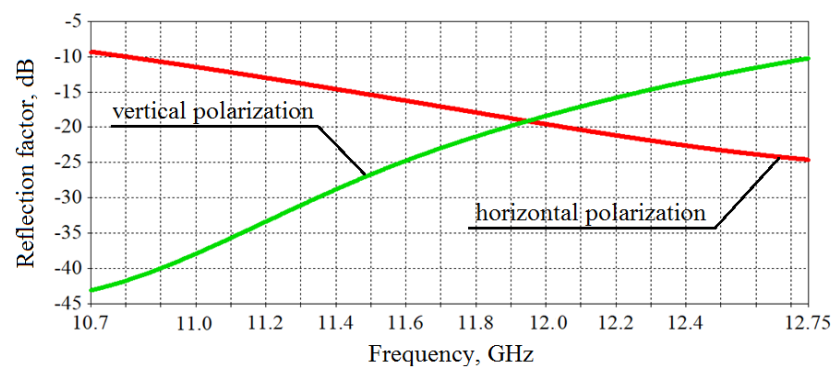

(b)

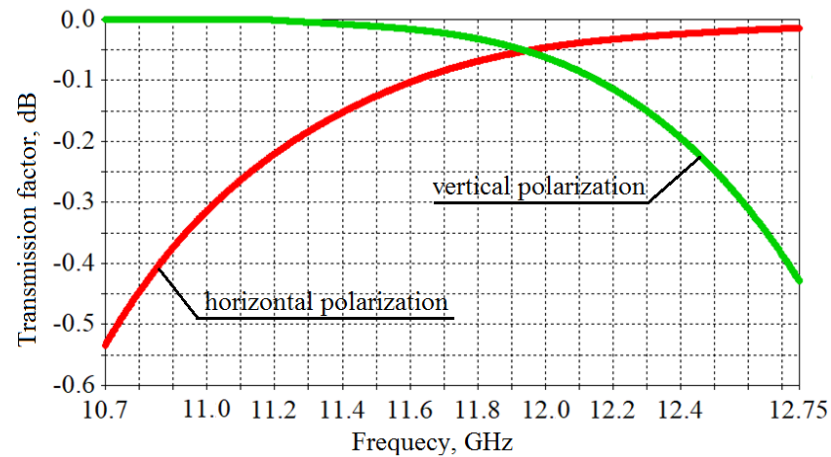

(c)

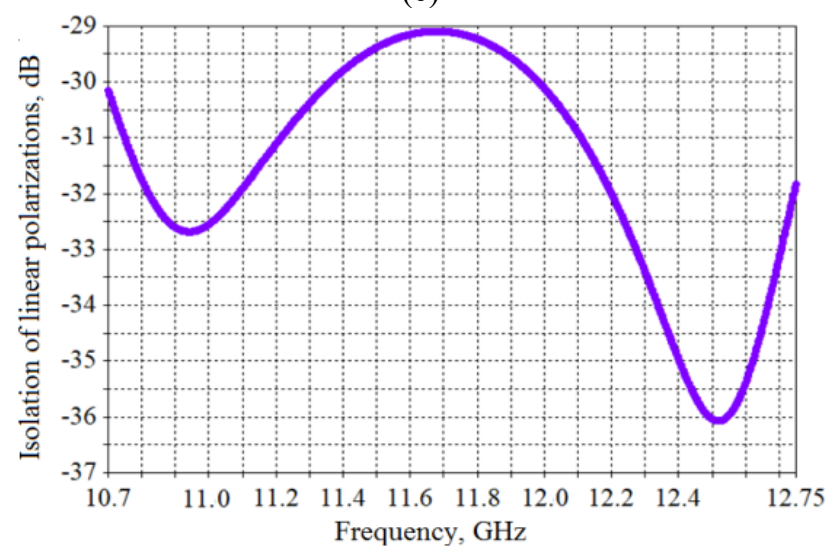

(d)

FIGURE 2. Main electromagnetic parameters of a a square guide polarizer with three diaphragms, (a) output phase difference, (b) reflection factor, (c) transmission factor, (d) isolation of linear polarization

Fig. 2a presents the function of output phase difference on frequency in Ku-band $10.7-12.75 \mathrm{GHz}$. As one can observe, the output phase difference is equal to $90^{\circ}$ at the frequencies of $10.76 \mathrm{GHz}$ and $12.63 \mathrm{GHz}$. In the operating frequency interval $10.7-12.75 \mathrm{GHz}$ the output phase difference changes from $86^{\circ}$ to $91^{\circ}$. It is seen in Fig. 2a that at $11.7 \mathrm{GHz}$ the highest deviation of the output phase difference from $90^{\circ}$ is equal to $4^{\circ}$.

Fig. $2 b$ shows the functions of reflection factor on frequency for both linear perpendicular polarizations in the frequency interval $10.7-12.75 \mathrm{GHz}$. It is seen that the highest value of reflection factor for both polarizations for the guide polarizer with three diaphragms is $-9.0 \mathrm{~dB}$ and it is achieved at the minimum frequency $10.7 \mathrm{GHz}$. Fig. 2c presents transmission factors for both linear polarizations in the frequency interval $10.7-12.75 \mathrm{GHz}$. It is seen that the minimal value of transmission factor for both polarizations is $-0.54 \mathrm{~dB}$ and it occurs at the minimum frequency 10.7 GHz. The function of ILP in the frequency interval 10.7$12.75 \mathrm{GHz}$ is presented in Fig. 2d. As one can indicate in Fig. 2d, the ILP of this guide polarizer is higher than $-29 \mathrm{~dB}$. The lowest ILP appears at the frequency of $11.7 \mathrm{GHz}$, which agrees with the frequency of the highest deviation of output phase difference of the optimized device from $90^{\circ}$. Moreover, two minimum values of ILP can be observed at the frequencies of $10.93 \mathrm{GHz}$ and $12.51 \mathrm{GHz}$, which does not exactly coincide with the frequencies at which the output phase difference is $90^{\circ}$. This discrepancy is explained by a significant influence of the frequency characteristics of reflection and transmission factors, which differ for vertical and horizontal linear polarizations.

Therefore, by applying three or more diaphragms in the construction of a guide polarizer one can get the output phase difference, which is quite close to $90^{\circ}$ in frequency interval 10.7-12.75 GHz, but the corresponding ILP does not reach the required level of $30 \mathrm{~dB}$. Besides, there remains bad matching of the developed guide polarizer with 3 diaphragms. The reason of this is a small number of diaphragms in the construction, which cannot compensate for reflections of electromagnetic waves at them. Consequently, to obtain required matching of the developed guide polarizer it is necessary to increment the number of applied diaphragms

\section{B. SQUARE GUIDE POLARIZER WITH FOUR DIAPHRAGMS}

A three-dimensional model and all sizes of a square waveguide polarizer with four diaphragms is shown in Fig. 1. The middle diaphragms have a height of $h_{2}$. They are higher than the other two diaphragms of the same height $h_{l}$ to ensure better matching. The distance between the central diaphragms is $L_{2}$, the distance between the central and external diaphragms is $L_{2}$. All diaphragms have the same thickness $w$. 

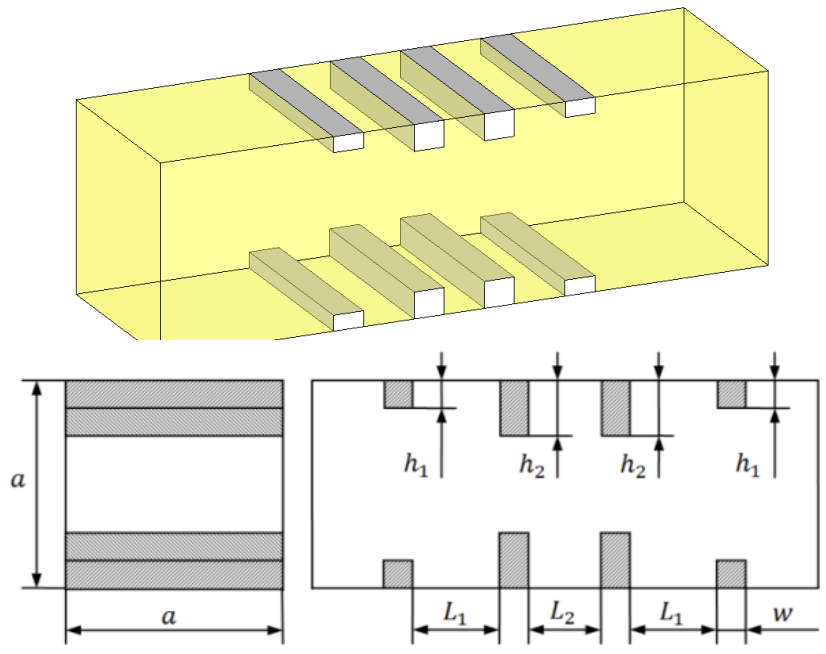

FIGURE 3.3-D model of a square guide polarizer with three diaphragms

Fig. 2 illustrates main parameters of the optimized compact square guide polarizer with four diaphragms in the operating Ku-band 10.7-12.75 GHz.

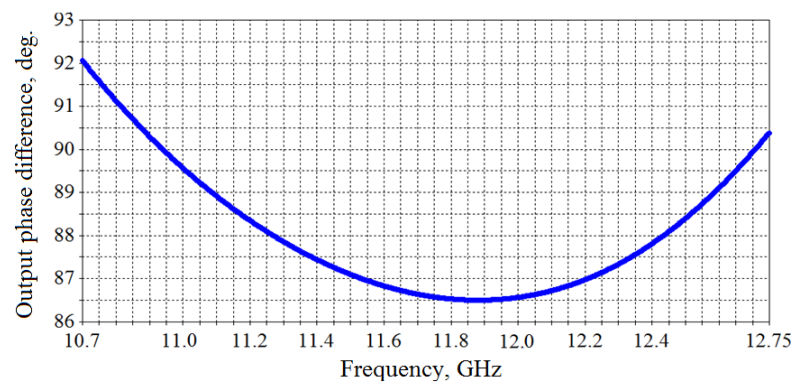

(a)

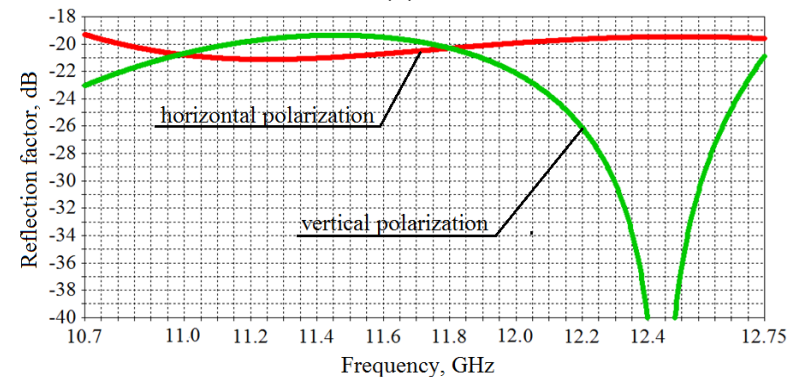

(b)

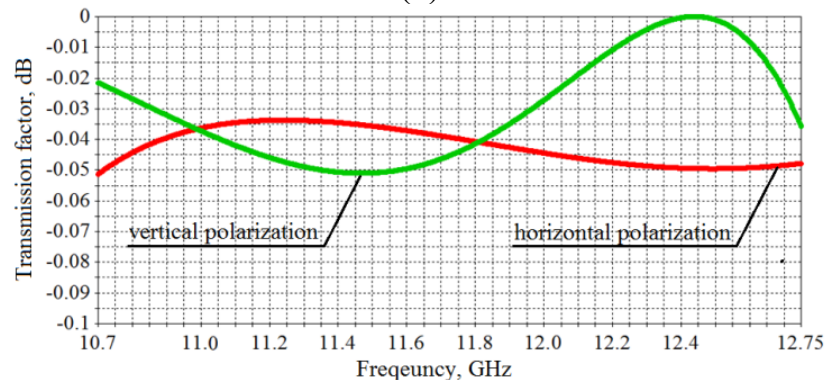

(c)

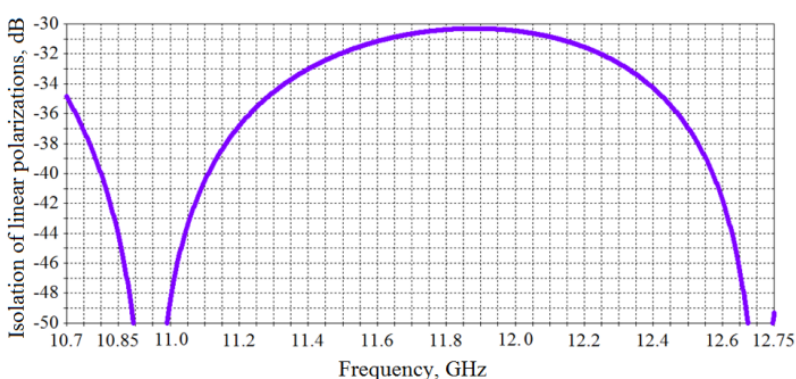

(d)

FIGURE 4. Main electromagnetic parameters of a a square guide polarizer with four diaphragms, (a) output phase difference, (b) reflection factor, (c) transmission factor, (d) isolation of linear polarization

Fig. 2a illustrates the output phase difference of the developed microwave device with four diaphragms. As one can observe, the output phase difference of a device is equal to $90^{\circ}$ at the frequencies $10.94 \mathrm{GHz}$ and $12.71 \mathrm{GHz}$. In the frequency interval $10.7-12.8 \mathrm{GHz}$ the output phase difference changes from $86.5^{\circ}$ to $92.1^{\circ}$. At the frequency of $11.9 \mathrm{GHz}$ there occurs the largest difference of the output phase difference from $90^{\circ}$, which is equal to $3.5^{\circ}$.

The functions of reflection factor on frequency for linear polarizations in the operating band $10.7-12.8 \mathrm{GHz}$ are shown in Fig 6b. As one can see, the peak level of reflection factors for both polarizations is $-19 \mathrm{~dB}$. Fig. 2c presents transmission factor for both polarizations in the frequency interval $10.7-12.75 \mathrm{GHz}$. It is worth nothing that the minimal value of reflection factor for both polarizations is $-0.05 \mathrm{~dB}$ and it is reached at the frequencies of $10.7 \mathrm{GHz}$ and $12.43 \mathrm{GHz}$. The function of ILP on frequency in the operating band $10.7-12.75 \mathrm{GHz}$ is indicated in Fig. $2 \mathrm{~d}$. It is observed that the peak ILP level is $30.3 \mathrm{~dB}$. It is seen that the lowest ILP and the maximum difference of output phase difference of a polarizer from $90^{\circ}$ are reached at the frequency of $11.9 \mathrm{GHz}$. In addition, two minimum values of IPL are observed at the frequencies 10.94 and $12.71 \mathrm{GHz}$, at which the output phase difference is $90^{\circ}$.

Hence, in the frequency interval $10.7-12.75 \mathrm{GHz}$ the designed polarizer with four diaphragms has the following parameters: the output phase difference is in the range $90^{\circ}$ $\pm 3.5^{\circ}$, reflection factor of both perpendicular linear polarizations is less than $-19 \mathrm{~dB}$, the transmission factor is greater than $-0.05 \mathrm{~dB}$, the ILP is better than $30.3 \mathrm{~dB}$. Therefore, the proposed guide polarizer with four diaphragms maintains required polarization purity parameters, but it demands further improvement of its matching.

\section{SQUARE GUIDE POLARIZER WITH FIVE DIAPHRAGMS}

A three-dimensional model of the analyzed square guide polarizer with five diaphragms is shown in Fig. 1. The construction of this microwave device is such as the ones examined hereinbefore. An additional diaphragm has been added in the middle. The length of central diaphragm $h_{3}$ is the highest, the lengths of two lower middle diaphragms are 
$h_{2}$ and the lengths of two outside diaphragms $h_{1}$ are the shortest ones. All used diaphragms have the same thickness $w$. The distances between the central and middle diaphragms are designated as $L_{1}$ and the distance between the outside and middle ones are denoted as $L_{2}$.
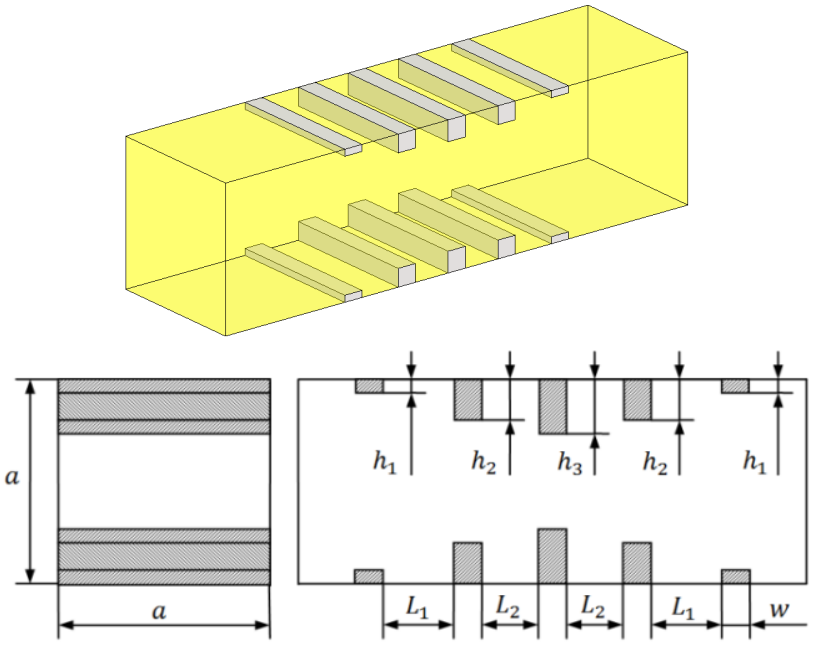

FIGURE 5.3-D model of a square guide polarizer with five diaphragms

Fig. 2 demonstrates main electromagnetic parameters of the developed guide polarizer with five diaphragms in the frequency interval $10.7-12.75 \mathrm{GHz}$.

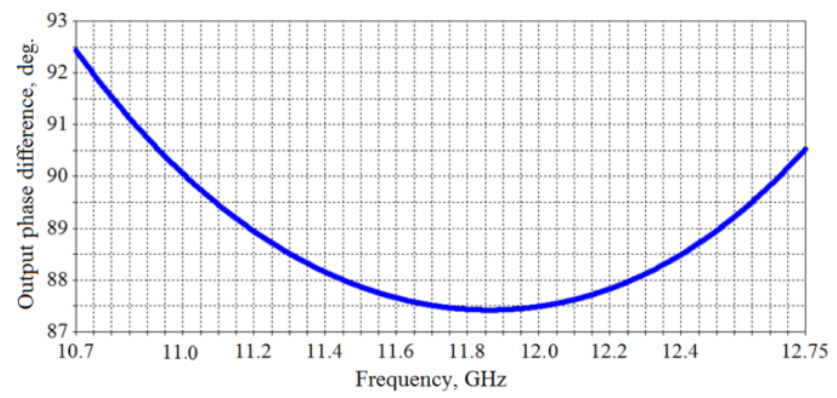

(a)

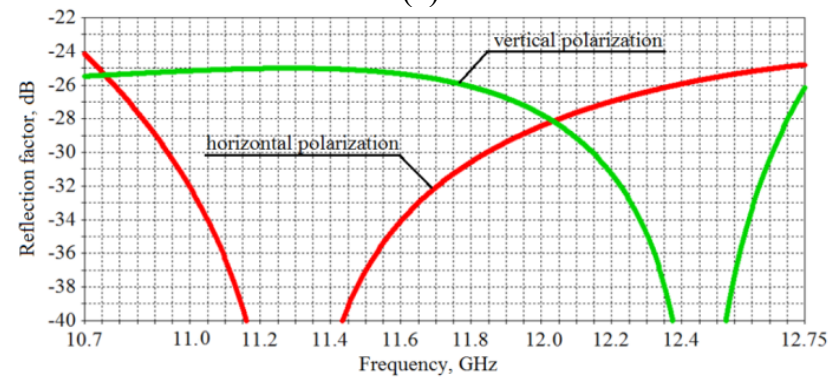

(b)

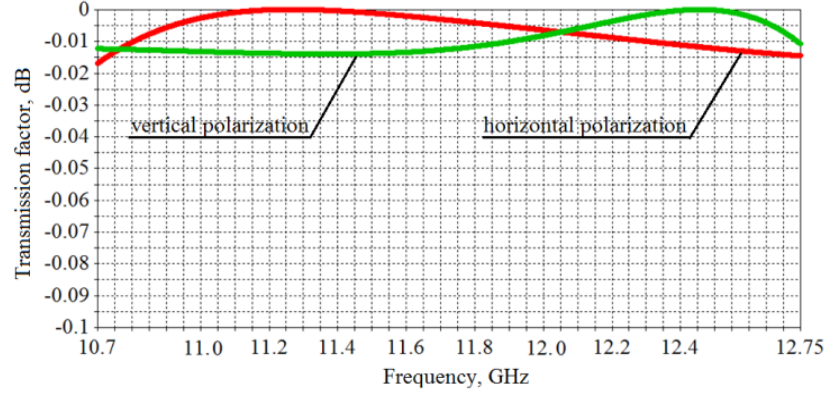

(c)

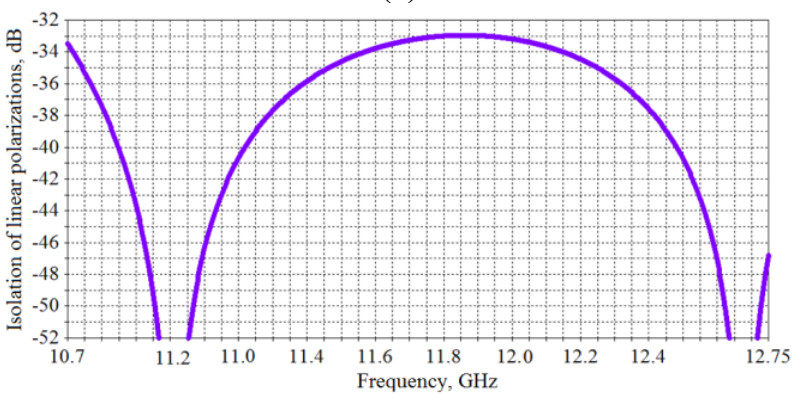

(d)

FIGURE 6. Main electromagnetic parameters of a a square guide polarizer with five diaphragms, (a) output phase difference, (b) reflection factor, (c) transmission factor, (d) isolation of linear polarization

Fig. 2a depicts the dependence of output phase difference on frequency. As one can observe, the output phase difference of the device is equal to $90^{\circ}$ at the frequencies $11.0 \mathrm{GHz}$ and $12.67 \mathrm{GHz}$. Within the frequency interval $10.7-12.75 \mathrm{GHz}$ the output phase difference of the polarizer alters from $87.4^{\circ}$ to $92.4^{\circ}$. Therefore, the output phase difference is $90^{\circ} \pm 2.6^{\circ}$. This change is minimum among all output phase differences of the considered guide polarizers.

The functions of reflection factors on frequency for both perpendicular linear polarizations are shown in Fig. 2 b. It is seen that in the operating band $10.7-12.75 \mathrm{GHz}$ the highest level of reflection factor is $-24 \mathrm{~dB}$ and it is reached at the frequency $10.7 \mathrm{GHz}$. In Fig. $2 \mathrm{~b}$ it is seen that the dependences of reflection factors of the developed polarizer with five diaphragms on frequency are not monotonic functions in contrast to the ones obtained for the transducer of polarizations with two and three diaphragms. For main modes of vertical and horizontal linear polarizations the dependences of reflection factor on frequency have a single lowest value in the frequency interval $10.7-12.75 \mathrm{GHz}$, which indicates the perfect matching of the device. Fig. $2 \mathrm{c}$ presents transmission factors for both polarizations in the frequency interval $10.7-12.75 \mathrm{GHz}$. It is worth nothing that the minimal value of reflection factor for both polarizations is $-0.017 \mathrm{~dB}$ and it is achieved at the frequency $10.7 \mathrm{GHz}$. The frequency dependence of ILP of the presented polarizer is plotted in Fig. 2 d. It is seen that in the operating frequency band the ILP of the device is higher than $32.9 \mathrm{~dB}$. It should be noted that the worst ILP can be seen at the frequency $11.87 \mathrm{GHz}$, which coincides to the frequency of highest change of output phase difference of the device from $90^{\circ}$. Two minima of the ILP dependence 
correspond to frequencies of $11.0 \mathrm{GHz}$ and $12.68 \mathrm{GHz}$, which coincide with the frequencies where the output phase difference is equal to the value of $90^{\circ}$.

Consequently, in the frequency band $10.7-12.75 \mathrm{GHz}$ the developed square guide polarizer with five diaphragms provides the electromagnetic parameters as follows: the output phase difference is $90^{\circ} \pm 2.6^{\circ}$, the reflection factors for both perpendicular linear polarizations are lower than $-24 \mathrm{~dB}$, the transmission factors are higher than $-0.017 \mathrm{~dB}$, the ILP is higher than $-32.9 \mathrm{~dB}$. Therefore, the application of five diaphragms has allowed to obtain a guide polarizer design, which simultaneously satisfies the requirements to polarization purity and matching.

\section{Comparison of obtained results and discussion}

All designed compact polarization converters can be simply fabricated applying milling technology. Let us compare the sizes and electromagnetic parameters of the presented microwave devices depending on the number of applied diaphragms.

Table I demonstrates all inner sizes of the guide polarizer converters, which were designed for the operating frequency interval $10.7-12.75 \mathrm{GHz}$. As one can see in Table 1, the increment of number of diaphragms results in the decrement of the size $a$ of square guide walls, which improves the compactness of a guide polarizer in transversal directions.

Table II compares electromagnetic characteristics of the developed guide polarizers with number of diaphragms from 3 to 5 in the frequency interval $10.7-12.75 \mathrm{GHz}$.

TABLE I. DIMENSIONS OF THE SQUARE GUIDE POLARIZERS WITH DIAPHRAGMS

\begin{tabular}{cccc}
\hline \hline Number of diaphragms & three & four & five \\
\hline $\begin{array}{c}\text { Size of square guide walls }(\mathrm{a}), \mathrm{mm} \\
\text { Height of the lowest diaphragms }\left(\mathrm{h}_{1}\right),\end{array}$ & 21.98 & 21.61 & 21.49 \\
$\begin{array}{c}\mathrm{mm} \\
\text { Height of the medium diaphragms } \\
\left(\mathrm{h}_{2}\right),\end{array}$ & 3.86 & 2.99 & 2.64 \\
$\begin{array}{c}\text { Height of the highest diaphragms }\left(\mathrm{h}_{3}\right), \\
\mathrm{mm}\end{array}$ & - & - & 3.06 \\
$\begin{array}{c}\text { Gap between the outer diaphragms } \\
\left(\mathrm{L}_{1}\right), \text { mm }\end{array}$ & 4.92 & 5.86 & 6.06 \\
$\begin{array}{c}\text { Gap between the inner diaphragms } \\
\left(\mathrm{L}_{2}\right), \mathrm{mm}\end{array}$ & - & 4.68 & 5.48 \\
$\begin{array}{c}\text { Thickness of all diaphragms }(w), \\
\mathrm{mm}\end{array}$ & 2.79 & 3.44 & 2.88 \\
\hline \hline
\end{tabular}

TABLE II. ELECTROMAGNETIC PARAMETERS OF POLARIZERS WITH DIAPHRAGMS

\begin{tabular}{cccc}
\hline \hline Number of diaphragms & three & four & five \\
\hline Output phase difference & $90^{\circ} \pm$ & $90^{\circ} \pm$ & $90^{\circ} \pm$ \\
Maximum reflection factor, $\mathrm{dB}$ & $-9.0^{\circ}$ & $3.5^{\circ}$ & $2.6^{\circ}$ \\
Minimum transmission factor, $\mathrm{dB}$ & -0.53 & -23 & -24 \\
Minimum ILP, dB & 29.0 & 30.3 & -0.017 \\
\hline \hline
\end{tabular}

The increment of a number of diaphragms applied in the construction leads to the decrease of the output phase difference introduced by each diaphragm, because the total output phase difference at the device's output is close to $90^{\circ}$ in each case. This results in the decrement of heights of the diaphragms as their amount becomes greater, which is seen in Table 1. As it was expected, the decrement of the diaphragm heights results in the improvement of matching of the polarizer's structure, which is confirmed by Table 2 .

It is seen in the Table I that the increment of amount of the diaphragms leads to the increment of the gaps between them. This phenomenon can be explained based on the physics of the electromagnetic waves propagation in the microwave device. The increment of number of the diaphragms results in more low heights. Accordingly, each diaphragm would concentrate the electric field and its energy less intensively. Then matching of the polarizer's design is provided by the similar discontinuities, which would be placed at longer distances. The opposite physical phenomenon is observed in the matching resonators of ultrawideband quad-ridged antennas and orthomode transducers $[26,51]$, which are shorter than the quarterwavelength resonators.

As one can see in the Table I, the thickness of diaphragms of compact square guide polarizers in frequency interval $10.7-12.75 \mathrm{GHz}$ falls in the range 2.8 $3.4 \mathrm{~mm}$ and it weakly depends on the amount of diaphragms. The relative thickness of diaphragms is $(0.11-$ $0.13) \cdot \lambda_{0}$, where $\lambda_{0}$ stands for the length of wave at the centre frequency $11.75 \mathrm{GHz}$.

We see that in all optimized polarizer designs the height of the middle diaphragm and the gap between diaphragms weakly depend on the amount of diaphragms. Table 1 demonstrates that they fall in the ranges $2.99-3.86 \mathrm{~mm}$ (which is $(0.12-0.15) \cdot \lambda_{0}$ ) and $4.92-6.06 \mathrm{~mm}$ (which is $\left.(0.19-0.24) \cdot \lambda_{0}\right)$, respectively. Hence, in all designed constructions of polarizers the height of the middle diaphragm is approximately equal to the diaphragm thickness, and the gap between diaphragms is 1.4-2.1 times greater than their thickness.

It is seen in the Table II that the guide polarizers with 3 and 4 diaphragms do not ensure required in most feed systems matching, because the maximum level of reflection factor is much greater than $-24 \mathrm{~dB}$. Besides, it can be seen from Table 2 that the minimum ILP level of the polarization converters with 3 and 4 diaphragms is less than $32 \mathrm{~dB}$. Accordingly, to provide simultaneously good matching and polarization electromagnetic characteristics in the operating frequency band $10.7-12.75 \mathrm{GHz}$ five or more diaphragms must be applied in the construction of polarization converter based on square guide with the conducting diaphragms.

\section{CONCLUSIONS}

In this article we developed compact guide polarizers with diaphragms and carried out their comparative analysis. A comparison was made for the electromagnetic 
characteristics and inner dimensions of square guide polarizers with different number of diaphragms from 3 to 5 .

In the operating frequency band $10.7-12.75 \mathrm{GHz}$ the square guide polarizer with five diaphragms ensured excellent performance with the following characteristics: the reflection factor is less than $-24 \mathrm{~dB}$ and the transmission factor is greater than $-0.017 \mathrm{~dB}$ for both perpendicular linear polarizations, the output phase difference is $90^{\circ} \pm 2.6^{\circ}$, the isolation of linear polarizations is less than $-32.9 \mathrm{~dB}$.

Consequently, the designed square guide polarization converter with five diaphragms has effective performance combined with a compact design. Obtained in this research results can be applied for the development of new guide polarizers for satellite communication systems and radars.

\section{REFERENCES}

[1] W. L. Stutzman, G.A. Thiele, Antenna Theory and Design. New Jersey, USA: John Wiley and Sons, 2013.

[2] S. Gao, F. Zhu, Circular polarized Antenna Theory and Design. Chichester, USA: John Wiley and Sons, 2013.

[3] W. L. Stutzman, Polarization in Electromagnetic Systems. Norwood, MA, USA: Artech House, 2018.

[4] Y. Huang, K. Boyle, Antennas: From Theory to Practice. Chichester, USA: John Wiley and Sons, 2008.

[5] K. Chang, Encyclopedia of $R F$ and Microwave Engineering. New Jersey, USA: John Wiley and Sons, 2005.

[6] R.E. Collin, Foundations for Microwave Engineering. New Jersey, USA: John Wiley and Sons, 2001.

[7] R. Sorrentino, G. Bianchi, Microwave and RF Engineering. New Jersey, USA: John Wiley and Sons, 2010.

[8] D.M. Pozar, Microwave Engineering. New Jersey, USA: John Wiley and Sons, 2012.

[9] N. Kinayman, M.I. Aksum, Modern Microwave Circuits. Norwood, USA: Artech House, 2005.

[10] S.A. Maas, Practical microwave circuits. Norwood, USA: Artech House, 2014.

[11] J. A. Ruiz-Cruz, et al., "Waveguide antenna feeders with integrated reconfigurable dual circular polarization", IEEE Transactions on Microwave Theory and Techniques, vol. 59, no. 12, pp. 3365-3374, December 2011. DOI: 10.1109/TMTT.2011.2170581.

[12] A.A. Kirilenko, et al., "Compact septum polarizer with a circular output waveguide", IEEE The Fifth International Kharkov Symposium on Physics and Engineering of Microwaves, Millimeter, and Submillimeter Wave, Kharkov, Ukraine, $2004 . \quad$ DOI: 10.1109/MSMW.2004.1346088.

[13] I. Kim I, Y. Rahmat-Samii, "Revisiting stepped septum circular polarizer using full-wave simulations", IEEE International Symposium on Antennas and Propagation, Spokane, USA, 2011. DOI: 10.1109/APS.2011.5996425.

[14] J. Kim, et al., "Triangular-shaped stepped septum polarizer for satellite communication", IEEE International Symposium on Antennas and Propagation, Spokane, USA, 2001, pp. 854-857. DOI: 10.1109/APS.2011.5996409.

[15] A. Mediavilla, J.L. Cano, and K. Cepero, "Compact quasi-octave bandwidth phase matched $\mathrm{K} / \mathrm{Ka}$ antenna feed subsystem for dual RHCP/LHCP polarization", European Microwave Conference, Amsterdam, Netherlands, 2011, pp. 1099-1102. DOI: 10.23919/EuMC.2012.6459338.

[16] W. Zhong, B. Li, Q. Fan, and Z. Shen, "X-band Compact Septum Polarizer Design", IEEE Int. Conf. on Microwave Technology and Computational Electromagnetics, Beijing, China, 2011, pp. 167-170. DOI: 10.1109/ICMTCE.2011.5915191.
[17] X. Wang, X. Huang, and X. Jin, "Novel square/rectangle waveguide septum polarizer", IEEE International Conference on Ubiquitous Wireless Broadband, Nanjing, China, 2016. DOI: 10.1109/ICUWB.2016.7790510.

[18] F.F. Dubrovka, et al, "Optimum septum polarizer design for various fractional bandwidths", Radioelectronics and Communications Systems, vol. 63, no.1, pp. 15-23, 2020. DOI: $10.3103 / \mathrm{S} 0735272720010021$.

[19] N. Nikolic, et al., "A septum polarizer with integrated square to circular tapered waveguide transition", IEEE International Symposium on Antennas and Propagation \& USNC/URSI National Radio Science Meeting, Boston, USA, 2018, pp. 725-726. DOI: 10.1109/APUSNCURSINRSM.2018.8608909.

[20] G. Jazani, A. Pirhadi, "Design of dual-polarised (RHCP/LHCP) quad-ridged horn antenna with wideband septum polariser waveguide feed", Microw. Antennas Propag., Vol. 12, no. 9, pp. 1541-1545, 2018. DOI: 10.1049/iet-map.2017.0611.

[21] J.-C. Angevain, N.J.G. Fonseca, "Waveguide septum polarizer shaped with Legendre polynomials", 11th European Conference on Antennas and Propagation, Paris, Frence, 2017, pp. 2286-2290. DOI: $10.23919 /$ EuCAP.2017.7928324.

[22] C.A. Leal-Sevillano, et al., "A $225 \mathrm{GHz}$ circular polarization waveguide duplexer based on a septum orthomode transducer polarizer", IEEE Trans. Terahertz Science and Technology, Vol 3, no 5, pp. 574-583, 2020. DOI: 10.1109/TTHZ.2013.2264317.

[23] F. Dubrovka, et al, "Compact X-band stepped-thickness septum polarizer", IEEE Ukrainian Microwave Week (UkrMW), Kharkiv, Ukraine, 2020, pp. 135-138. DOI: 10.1109/UkrMW49653.2020.9252583.

[24] F. Dubrovka, et al., "Circularly polarised X-band H11- and H21modes antenna feed for monopulse autotracking ground station", IEEE Ukrainian Microwave Week, Kharkiv, Ukraine, September 2020, pp. 196-202. DOI: 10.1109/UkrMW49653.2020.9252600.

[25] B. Deutschmann, A. F. Jacob, "Broadband septum polarizer with triangular common port," IEEE Transactions on Microwave Theory and Techniques, vol. 68, no. 2, pp. 693-700, 2020. DOI: 10.1109/TMTT.2019.2951138.

[26] S.I. Piltyay, "Enhanced C-band coaxial orthomode transducer", Visnyk NTUU KPI Seriia - Radiotekhnika, Radioaparatobuduvannia, Vol. 58, pp. 35-42, 2014. DOI: 10.20535/RADAP.2014.58.35-42.

[27] B.M. Park, P. Ramunujam, F. Boldissar, and C. Shin, "Sensitivity analysis of square waveguide iris polarizers", IEEE Antennas and Propagation Societly International Symposium and URSI National Radio Science Meeting, Seattle, USA, 1994. DOI: 10.1109/APS.1994.407908.

[28] G. Bertin, B. Piovano, L. Accatino, and M. Mongiardo, "Full-wave design and optimization of circular waveguide polarizers with elliptical irises", IEEE Transactions on Microwave Theory and Techniques, Vol. 50, no 4, pp. 1077-1083, 2002. DOI: $10.1109 / 22.993409$.

[29] V.I. Abramov, T.-H. Lee, and H.-J. Park, "Compact square waveguide iris polarizer for rotation of linear polarization", European Microwave Conference, Paris, Frence, 2005. DOI: 10.1109/EUMC.2005.1610103.

[30] G. Virone, et al., "A novel design tool for waveguide polarizer", IEEE Transactions on Microwave Theory and Techniques, Vol. 53, no 3, pp. 888-894, 2005. DOI: 10.1109/TMTT.2004.842491.

[31] G. Virone, et al., "Optimum-Iris-Set Concept for Waveguide Polarizers", IEEE Microwave and Wireless Compon. Letters, Vol. 17, no 3, pp. 202-204, 2007. DOI: 10.1109/LMWC.2006.890474.

[32] S.-M. Hwang, B.-C. Ahn, "New design method for a dual band waveguide iris polarizer", IEEE International Symposium on Microwave, Antenna, Propagation, and EMC Technologies For Wireless Communications, Hangzhou, China, 2007, pp. 435-438. DOI: 10.1109/MAPE.2007.4393644.

[33] Y. Liu, F. Li, X. Li, and H. He, "Design and optimization of wide and dual band waveguide polarizer", Global Symposium on Millimeter Waves, Nanjing, China, 2008, pp. 385-386. DOI: $10.1109 /$ GSMM.2008.4534654. 
[34] G. Virone, et al., "Combined-phase-shift waveguide polarizer", IEEE Microwave and Wireless Compon. Letters, Vol. 18, no 8, pp. 509-511, 2008. DOI: 10.1109/LMWC.2008.2001005.

[35] A. Tribak, A. Mediavilla, K. Cepero, and J.L. Cano, “Compact K/Ka 4-port feed subsystem for dual circular polarization”, European Microwave Conference, Manchester, United Kingdom, pp. 10311034, 2011. DOI: 10.23919/EuMC.2011.6101744.

[36] S.-M. Hwang, J.-M. Kim, and K.-H. Lee, "Study on design parameters of waveguide polarizer for satellite communication", IEEE Asia-Pacific Conference on Antennas and Propagation, Singapore, pp. 153-154, 2012. DOI: 10.1109/APCAP.2012.6333202.

[37] F.F. Dubrovka, S.I. Piltyay, "A novel wideband coaxial polarizer", IEEE International Conference on Antenna Theory and Techniques (ICATT), Odesa, Ukraine, 2013, pp. 473-474 DOI: 10.1109/ICATT.2013.6650816.

[38] M.-H. Chung, D.-H. Je, and S.-T. Han, "Development of a 85 115 $\mathrm{GHz}$ 9-deg phase shifter using corrugated square waveguide", European Microwave Conference, Rome, Italy, 2014, pp. 1146-1149. DOI: 10.1109/EuMC.2014.6986643.

[39] Yu. Tikhov, "Comparison of two kinds of Ka-band circular polarisers for use in a gyro-travelling wave amplifier", IET Microwaves, Antennas and Propagation, Vol. 10, no 2, pp. 147-151, 2016. DOI 10.1049/iet-map.2015.0292.

[40] S. I. Piltyay, "High performance extended C-band 3.4-4.8 GHz dual circular polarization feed system", XI International Conference on Antenna Theory and Techniques (ICATT), Kyiv, Ukraine, May 2017, pp. 284-287. DOI: 10.1109/ICATT.2017.7972644.

[41] S. I. Piltyay, A. V. Bulashenko, and I. V. Demchenko, "Waveguide iris polarizers for Ku-band satellite antenna feeds", Journal of Nanoand Electronic Physics, vol. 12, no. 5, pp. 05024-1-05024-5, October 2020. DOI: 10.21272/jnep.12(5).05024.

[42] S.I. Piltyay, O. Yu. Sushko, A. V. Bulashenko, and I. V. Demchenko, "Compact $\mathrm{Ku}$-band iris polarizers for satellite telecommunication systems", Telecommunications and Radio Engineering, vol. 79, no. 19, pp. 1673-1690, 2020. DOI: 10.1615/TelecomRadEng.v79.i19.10.

[43] S. I. Piltyay, A. V. Bulashenko, and I. V. Demchenko, "Compact polarizers for satellite information systems", IEEE International Conference on Problems of Infocommunications. Science and Technology, Kharkiv, Ukraine, October 2020, pp. 350-355.

[44] F. F. Dubrovka, S. I. Piltyay, "Eigenmodes of sectoral coaxial ridged waveguides", Radioelectronics and Commun. Systems, vol. 55, no. 6, pp. 239-247. June 2012. DOI: 10.3103/S0735272712060015.

[45] S. I. Piltyay, "Numerically effective basis functions in integral equation technique for sectoral coaxial ridged waveguides", 14-th International Conference on Mathematical Methods in Electromagnetic Theory (MMET), Kyiv, Ukraine, August 2012, pp. 492-495. DOI: 10.1109/MMET.2012.6331195.

[46] F. F. Dubrovka, S. I. Piltyay, "Eigenmodes of coaxial quad-ridged waveguides. Theory", Radioelectronics and Communications Systems, vol. 57, no. 1, pp. 1-30. January 2014. DOI: $10.3103 / \mathrm{S} 0735272714010014$.

[47] F. F. Dubrovka, S. I. Piltyay, "Eigenmodes of coaxial quad-ridged waveguides. Numerical results", Radioelectronics and Communications Systems, vol. 57, no 2, pp. 59-69, 2014. DOI: 10.3103/S0735272714020010

[48] L.A. Rud, K.S. Shpachenko, "Polarizers on sections of square waveguides with inner corner ridges", IEEE VIII International Conference on Antenna Theory and Techniques, Kyiv, Ukraine, 2011. DOI: 10.1109/ICAT.2011.6170775.

[49] C. Granet, et al., "The designing, manufacturing, and testing of a dual-band feed system for the Parkes radio telescope", IEEE Antennas and Propagation Magazine, Vol. 47, no 3, pp. 13-19, 2005. DOI: 10.1109/MAP.2005.1532537.

[50] H.Z. Zhang, "An integrated coaxial circular-polarised OMJ/OMT for dual-band feed applications", IEEE International Antennas and Propagation Symposium Digest, Washington, Vol. 43, pp. 647-650, 2005. DOI: 10.1109/APS.2005.1551894.

[51] F. F. Dubrovka, S. I. Piltyay, "A high performance ultrawideband orthomode transducer and a dual-polarized quad-ridged horn antenna based on it", Proceedings of VIII Int. Conf. on Antenna Theory and Techniques (ICATT), Kyiv, Ukraine, September 2011, pp. 176-178. DOI: 10.1109/ICATT.2011.6170737.

[52] A. Tribak, A. Mediavilla, J.L. Cano, M. Boussouis, and K. Cepero "Ultra-broadband low axial ratio corrugated quad-ridge polarizer", European Microwave Conference, Rome, Italy, 2009, pp.73-74. DOI: 10.23919/EUMC.2009.5295927.

[53] F. F. Dubrovka, S. I. Piltyay, "Novel high performance coherent dual-wideband orthomode transducer for coaxial horn feeds", $X I$ International Conference on Antenna Theory and Techniques (ICATT), Kyiv, Ukraine, May 2017, pp. 277-280. DOI: 10.1109/ICATT.2017.7972642.

[54] A.W. Pollak, M.E. Jones, "A compact quad-ridge orthogonal mode transducer with wide operational bandwidth", IEEE Antennas and Wireless Propagation Letters, Vol. 17, no 3, pp. 422-425, 2018. DOI: 10.1109/LAWP.2018.2793465.

[55] N. Kolmakova, et al., "Simple example of polarization plane rotation by the fringing fields interaction", European Microwave Conference, Nuremberg, Germany, 2013. DOI: 10.1109/EuMC.2013.6686812.

[56] A. Kirilenko, S. Steshenko, Ye. Ostryzhnyi, "Topology of a planarchiral iris as factor in controlling the "optical activity" of bilayer object”, IEEE Ukrainian Microwave Week, Kharkiv, Ukraine, 2020. DOI: 10.1109/UkrMW49653.2020.9252669.

[57] N. Kolmakova, S. Prikolotin, A. Perov, V. Derkach, and A. Kirilenko, "Polarization plane rotation by arbitrary angle using D4 symmetrical", IEEE Transactions on Microwave Theory and Techniques, Vol. 64, no 2, pp. 429-435, 2016. DOI: 10.1109/TMTT.2015.2509966.

[58] D.Yu. Kulik, S.O. Steshenko, and A.A. Kirilenko, "Compact polarization plane rotator for arbitrary angle", XI International Conference on Antenna Theory and Techniques, Kiev, Ukraine, 2017. DOI: 10.1109/ICATT.2017.7972641.

[59] A.A. Kirilenko, et al., "A tunable compact polarizer in a circular waveguide", IEEE Transactions on Microwave Theory and Techniques, Vol. 67, no 2, pp. 592-596, 2019. DOI: 10.1109/TMTT.2018.2881089.

[60] D.Yu. Kulik, L.P. Mospan, A.O. Perov, and N.G. Kolmakova, "Compact-size polarization rotators on the basis of irises with rectangular slots", Telecommunications and Radio Engineering, Vol. 75, no 10, pp. 857-865, 2016. DOI: 10.1615/TelecomRadEng.v75.i10.10.

[61] J. Roelvink, A. Williamson, "Multi-element variable-length cylindrical posts in rectuangular waveguide", IEEE MTT-S International Microwave Symposium Diest, San Francisco, USA, 2006. DOI: 10.1109/MWSYM.2006.249573.

[62] Q.C. Zhu, A.G. Williamson, and J.M. Neve, "Reactance of posts in circular waveguide", IEEE Transactions on Microwave Theory and Techniques, Vol. 55, no 8, pp. 1685-1688, 2007. DOI: 10.1109/TMTT.2007.901605.

[63] A.A. Kirilenko, D.Yu. Kulik, L.P. Mospan, and L.A. Rud, "Reflection resonances in a waveguide section with two uneven post", Telecommunications and Radio Engineering, Vol. 68, no 11, pp. 933-942, 2009. DOI: 10.1615/TelecomRadEng.v68.i11.10.

[64] S.B. Sharma, V.K. Singh, R. Dey, and S. Chakrabarty, "Analysis of a post discontinuity in an oversized circular waveguide", IEEE Transactions on Microwave Theory and Techniques, Vol. 57, no 8, pp. 1989-1995, 2009. DOI: 10.1109/TMTT.2009.2025448.

[65] L.P. Mospan, et al., "Rectangular waveguide section with a pair of antipodal posts: spectral characteristics", IEEE International Conference on Antenna Theory and Techniques, Kharkiv, Ukraine, 2015. DOI: 10.1109/ICATT.2015.7136867.

[66] L. Polo-Lopez, J.L. Masa-Campos, and J.A. Ruiz-Cruz, "Design of a reconfigurable rectangular waveguide phase shifter with metallic posts", European Microwave Conference, Nuremberg, Germany, 2017. DOI: 10.23919/EuMC.2017.8231036.

[67] A. Chittora, "Periodic metallic posts loaded compact TM01-TE11 mode converter", IEEE Asia-Pacific Conference on Applied Electromagnetics, Melacca, Malaysia, 2019. DOI: 10.1109/APACE47377.2019.9020921. 
[68] L. Mospan, S. Steshenko, "A multi-function resonator based on an asymmetric tri-post rectangular waveguide section", IEEE European Microwave Conference in Central Europe (EuMCE), Prague, Czech Republic, May 2019.

[69] S. Piltyay, A. Bulashenko, H. Kushnir, and O. Bulashenko, "Information resources economy in satellite systems based on new microwave polarizers with tunable posts", Path of Science, vol. 6, no 11, pp. 5001-5010. DOI: 10.22178/pos.55-1.

[70] A. Bulashenko, S. Piltyay, et al., "Mathematical modeling of iris-post sections for waveguide filters, phase shifters and polarizers", IEEE 2nd International Conference on Advanced Trends in Information Theory (ATIT), Kyiv, Ukraine, November 2020, pp. 330-336. DOI: 10.1109/ATIT50783.2020.9349321

[71] S. Piltyay, A. Bulashenko, O. Sushko, et al., "Analytical modeling and optimization of new Ku-band tunable square waveguide iris-pos polarizer," International Journal of Numerical Modelling: Electronic Networks, Devices and Fields, vol. 34, no. 4, pp. 1-27, 2021 DOI: $10.1002 / J N M .2890$

[72] S. Piltyay, A. Bulashenko, H. Kushnir, and O. Bulashenko, "New tunable iris-post square waveguide polarizers for satellite information systems", IEEE 2nd International Conference on Advanced Trends in Information Theory (ATIT), Kyiv, Ukraine, November 2020, pp. 342-348. DOI: 10.1109/ATIT50783.2020.9349357.

[73] K. Roman, J. Semenjako, and Yu. Shestopalov, "Fast method for analysis of multiple H-plane cylindrical posts with multiple cylindrical inclusions in a rectangular waveguide", IEEE Microwave Theory and Techniques in Wireless Communications, Riga, Latvia, 2020 DOI: 10.1109/MTTW51045.2020.9244922.

[74] U. Tucholke, F. Arndt, and T. Wriedt, "Field theory design of square waveguide iris polarizers", IEEE Transactions on Microwave Theory and Techniques., Vol. 34, no 1, pp. 156-160, 1986. DOI: 10.1109/TMTT.1133293

[75] T. Vasileva, et al., "Calculation of full-wave S-matrices of monoaxially uniform (2D) elements in rectangular waveguides", International Conference on Mathematical Methods in Electromagnetic Theory, Kharkov, Ukraine, 1998. DOI: 10.1109/MMET.1998.709990.

[76] B. Subbarao, V.F. Fusco, "Compact coaxial-fed CP polarizer", IEEE Antennas and Wireless Propagation Letters, Vol. 3, pp. 145-147, 2004. DOI: 10.1109/LAWP.2004.831084

[77] A.A. Kirilenko, et al., "The assembling scheme in S-matrix based ful-wave electromagnetic modeling systems", International Conference on Antenna Theory and Techniques, Kyiv, Ukraine, 2005. DOI 10.1109/ICATT.2005.1497019.

[78] A.A. Kirilenko, et al., "Stepped approximation technique in the problem on polarizer based on circular waveguide with rectangular ridges", 5th International Conference on Antenna Theory and Techniques, Kyiv, Ukraine, 2005. DOI: 10.1109/ICATT.2005.1497018.

[79] A.A. Kirilenko, et al., "Stepped approximation technique for designing coaxial waveguide polarizer", IEEE IX International Conference on Antenna Theory and Techniques, Odessa, Ukraine, 2013. DOI: 10.1109/ICATT.2013.6650815.

[80] A. V. Bulashenko, S. I. Piltyay, and I. V. Demchenko, "Wave matrix technique for waveguide iris polarizers simulation. Theory", Journal of Nano- and Electronic Physics, vol. 12, no. 6, pp. 06026-1-060265, December 2020. DOI: 10.21272/jnep.12(6).06026.

[81] A. V. Bulashenko, S. I. Piltyay, and I. V. Demchenko, "Wave matrix technique for waveguide iris polarizers simulation. Numerical results", Journal of Nano- and Electronic Physics, vol. 13, no. 3, pp. 03023, 2021. DOI: 10.21272/jnep.13(3).03023.

[82] A.V. Bulashenko, S.I. Piltyay, "Equivalent microwave circuit technique for waveguide iris polarizers development", Visnyk NTUU KPI Seriia - Radiotekhnika, Radioaparatobuduvannia, Vol. 83, pp 17-28. 2020. DOI: 10.20535/RADAP.2020.83.17-28.

[83] S. I. Piltyay, A. V. Bulashenko, and I. V. Demchenko, "Analytical synthesis of waveguide iris polarizers", Telecommunications and Radio Engineering, vol. 79, no. 18, pp. 1579-1597, November 2020. DOI: 10.1615/TelecomRadEng.v79.i18.10.

[84] A.V. Bulashenko, S.I. Piltyay, and I.V. Demchenko, “Optimization of a polarizer based on a square waveguide with irises", Science-
Based Technologies, Vol. 47, no 3, pp. 287-297, 2020. (in Ukrainian). DOI: 10.18372/2310-5461.47.14878.

[85] S. Nandi, T.S. Indumathi, "Mathematical analysis and representation of the transverse electric modes of the symmetric slab waveguide", IEEE Int. Conf. on Electronics, Computing and Technologies, Bangalore, India, 2020. DOI: 10.1109/CONECCT50063.2020.9198469.

[86] Y.-X. Zhang, et al., "Wideband inhomogeneous-polarizer loaded polarized SIW horn antennas for broadband millimeter-wave applications", IEEE Antennas and Wireless Propagation Letters, vol 18, no 7, pp. 1448-1452, 2019. DOI: 10.1109/LAWP.2019.2919636.

[87] C. Shu, J. Wang, and X. Chen, "A wideband dual-circularpolarization horn antenna for mmWave wireless communications", IEEE Antennas and Wireless Propagation Letters, Vol. 18, no 9, pp 1726-1730, 2019. DOI: 10.1109/LAWP.2019.2927933.

[88] E. Wang, T. Zhang, D. He, L. Chen, and J. Yang, "Wideband highgain circularly polarized antenna array on gap waveguide for $5 \mathrm{G}$ application", International Symposium on Antennas and Propagation, Xi'an, China, 2019.

[89] B. Feng, et al., "A compact wideband circularly polarized magnetoelectric dipole antenna array for 5G millimeter-wave applications", IEEE Transactions on Antennas and Propagation, vol. 68, no 9, pp. 6838-6843, 2020. DOI: 10.1109/TAP.2020.2980368.

[90] A. Bulashenko, S. Piltyay, A. Polishchuk, and O. Bulashenko, "New traffic model of M2M Technology in 5G wireless sensor networks", IEEE 2nd International Conference on Advanced Trends in Information Theory, Kyiv, Ukraine, 2020, pp. 125-131. DOI: 10.1109/ATIT50783.2020.9349305.

[91] S. I. Piltyay, A. V. Bulashenko, et al., "Wireless sensor network connectivity in heterogeneous 5G mobile systems", IEEE International Conference on Problems of Infocommunications. Science and Technology, Kharkiv, Ukraine, 2020, pp. 508-513.

[92] A. V. Bulashenko, S. I. Piltyay, et al., "Energy efficiency of the D2D direct connection system in 5G networks", IEEE International Conference on Problems of Infocommunications. Science and Technology, Kharkiv, Ukraine, 2020, pp. 324-329

[93] K. Al-Amoodi, et al., "A compact substrate integrated waveguide notched-septum polarizer for 5G mobile devices", IEEE Antennas and Wireless Propagation Letters, Vol. 19, no 12, pp. 2517-2521, 2020. DOI: 10.1109/LAWP.2020.3038404.

[94] J.L. Cano, et al., "On the accurate full characterization of septum polarizers through simple amplitude measurements in back-to-back configuration", IEEE Trans.on Microwave Theory and Tech., vol. 69 , no 1, pp. 179-188, 2021. DOI: 10.1109/TMTT.2020.3020639.

[95] A. V. Bulashenko, S. I. Piltyay, and I. V. Demchenko, "Analytical technique for iris polarizers development", IEEE International Conference on Problems of Infocommunications. Science and Technology, Kharkiv, Ukraine, October 2020, pp. 464-469.

[96] S. Piltyay, A. Bulashenko, Y. Herhil, and O. Bulashenko, "FDTD and FEM simulation of microwave waveguide polarizers", IEEE 2nd International Conference on Advanced Trends in Information Theory (IEEE ATIT), Kyiv, Ukraine, November 2020, pp. 357-363. DOI: 10.1109/ATIT50783.2020.9349339.

[97] S. Piltyay, A. Bulashenko, and Y. Herhil, "Numerical performance of FEM and FDTD methods for the simulation of waveguide polarizers", Visnyk NTUU KPI Seriia - Radiotekhnika, Radioaparatobuduvannia, Vol. 84, pp. 11-21. 2021. DOI: 10.20535/RADAP.2021.84.11-21. 